\title{
Optimizing treatment of hepatic metastases from colorectal cancer: Resection or resection plus ablation?
}

\author{
ANTONIO CHIAPPA ${ }^{1}$, EMILIO BERTANI ${ }^{2}$, ANDREW P. ZBAR ${ }^{3,10}$, DIEGO FOSCHI $^{4}$, NICOLA FAZIO $^{5}$, \\ MARIA ZAMPINO $^{5}$, CLAUDIO BELLUCO ${ }^{6}$, FRANCO ORSI $^{7}$, PAOLO DELLA VIGNA ${ }^{7}$, GUIDO BONOMO ${ }^{7}$, \\ MARCO VENTURINO $^{8}$, CARLO FERRARI ${ }^{9}$ and ROBERTO BIFFI ${ }^{11}$
}

${ }^{1}$ Unit of Innovative Techniques in Surgery, European Institute of Oncology, University of Milan, Milan; ${ }^{2}$ Hepatobiliary Division, European Institute of Oncology, Milan, Italy; ${ }^{3}$ Department of General Surgery and Transplantation Chaim Sheba Medical Center, Sackler Medical School and Tel Aviv University, Tel Aviv, Israel; ${ }^{4}$ Complex Unit of General Surgery, Surgical-Oncologic and Gastroenterologic Department of 'Luigi Sacco' Hospital, Milan University of Milan, Milan; ${ }^{5}$ Unit of Medical Oncology, European Institute of Oncology, Milan; ${ }^{6}$ General Oncologic Surgery, Oncologic Hospital, Aviano; ${ }^{7}$ Interventional Radiology Division, European Institute of Oncology, Milan; ${ }^{8}$ Anaesthesiology Division, European Institute of Oncology, Milan; ${ }^{9}$ University of Milan, Milan; ${ }^{10}$ Department of Anatomy, University of Otago, Dunedin, New Zealand; ${ }^{11}$ Digestive Surgery, European Institute of Oncology, Milan, Italy

Received October 11, 2015; Accepted November 12, 2015

DOI: $10.3892 /$ ijo.2016.3324

\begin{abstract}
The present study determines the oncologic outcome of the combined resection and ablation strategy for colorectal liver metastases (CRLM). Between January 1994 and December 2014, 360 patients underwent surgery for CRLM. There were 280 patients who underwent hepatic resection only (group 1) and 80 hepatic resection plus ablation (group 2). Group 2 patients had a higher incidence of multiple metastases than group 1 cases (100\% in group 2 vs. $28.2 \%$ in group 1; $\mathrm{P}<0.001)$ and bilobar involvement $(76.5 \%$ in group 2 vs. $12.9 \%$ in group $1 ; \mathrm{P}<0.001)$. Perioperative mortality was nil in either group with a higher postoperative complication rate amongst group 1 vs. group 2 cases (18 vs. 0, respectively). The median follow-up was 90 months (range, 1-180) with a 5 -year overall survival for group 1 and group 2 of 49 and $80 \%$, respectively $(\mathrm{P}=0.193)$. The median disease-free survival for patients with R0 resection was 50, 43 and $34 \%$ at 1, 2 and 3 years, respectively, and remained steadily higher (at $50 \%$ ) in those patients treated with resection combined with ablation
\end{abstract}

Correspondence to: Professor Antonio Chiappa, Department of General Surgery, University of Milan, European Institute of Oncology, Via G. Ripamonti 435, I-20141 Milan, Italy

E-mail: antonio.chiappa@unimi.it; antonio.chiappa@ieo.it

Abbreviations: RFA, radiofrequency ablation; CRC, colorectal cancer; LM liver metastasis; IOUS, intraoperative ultrasound; CT, computed tomography; PET, positron emission tomography; CSAc cryosurgical ablation

Key words: hepatic metastases, colorectal cancer, liver resection, radiofrequency ablation, cryosurgical ablation up to 5 years $(\mathrm{P}=0.069)$. The only intraoperative ablation failure was for a large lesion $(\geq 5 \mathrm{~cm})$. Our data support the use of intraoperative ablation when complete hepatic resection cannot be achieved.

\section{Introduction}

More than 200,000 deaths from colorectal cancer (CRC) are reported in Europe annually (1) with little variation over the last 20 years in the incidence of hepatic metastatic disease as a first presentation (2). Despite the introduction of newer chemotherapies and targeted therapeutics as adjuvant treatments following radical colorectal resection, $60 \%$ of patients will eventually develop liver metastases (CRC LM) (3). Most of these patients have disseminated disease and if untreated, they have a median survival of $<1$ year. For the minority of patients with disease confined to the liver, hepatic resection with negative (R0) resection margins remains the only potentially curative therapy $(4,5)$. Despite a more aggressive surgical approach towards hepatic metastases, most patients with CRC LM even without demonstrable extrahepatic disease are not candidates for resection either because of bilobar disease that is not amenable to complete extirpation or where the extent of metastatic disease precludes the ability to leave a sufficiently functioning liver remnant. In an attempt to enhance resectability, several selective strategies have been tried including the use of neoadjuvant chemotherapy, 2-stage hepatectomy and preoperative portal vein embolization $(6,7)$ with only a limited number deemed suitable for either a formal hepatectomy or a non-anatomical wedge resection.

Interstitial thermo-ablative techniques such as radiofrequency ablation (RFA) permit parenchyma-sparing treatment of hepatic tumours in these clinical scenarios (8) with several studies reporting long-term survival following cryosurgical ablation (CSA) in selected cases $(9,10)$ although in this 
technique the instrumentation has proven cumbersome and substantial complication rates have been reported $(9,11)$. Radiofrequency ablation is currently the most commonly used ablative method with a number of studies reporting its inherent safety (12-14). Although RFA has traditionally been used in a palliative setting for CRC LM, it has been also utilized as an adjunct to resection designed to improve metastasis resectability. In this context the current data of combined resection plus thermo-ablation are limited and the oncologic outcome of this approach is uncertain (14,15-23). The aim of the present study is to review our experience of patients undergoing hepatic resection for CRC LM combined with intraoperative thermo-ablation and to analyze the safety, utility and oncologic outcome of this operative strategy.

\section{Materials and methods}

Data were obtained from a prospectively collated hepatobiliary surgery database in a dedicated oncology institute identifying a total of 360 patients with resected CRC LM was included in this analysis, treated during January 1994-December 2014. Of this total, 80 patients $(22 \%)$ underwent hepatic resection combined with additional thermo-ablative procedures as the primary treatment modalities. All patients routinely underwent preoperative abdominal and pelvic computed tomographic (CT) scans, chest roentgenograms or chest CT and colonoscopy. Other imaging studies such as ultrasonography, magnetic resonance imaging and positron emission tomography (PET) were obtained at the discretion of the treating surgeon. Preoperative chest CT and PET scanning was performed in $320(89 \%)$, and 307 (85\%) patients, respectively, in accordance with our previously published guidelines (24). Liver function was evaluated with standard serum biochemical tests and by the Childs-Pugh classification. No patients with biochemical evidence of cirrhosis were included in this series analysis.

A standardized approach to hepatic resection was used, which has been published $(4,24)$. Briefly, this method involves the use of low central venous blood pressure, vascular control, and parenchymal transection using a clamp-crushing technique with an intermittent Pringle maneuver. Intraoperative ultrasound (IOUS) was carried out in all patients and was also used to guide placement of the RFA needle electrode. With the application of radiofrequency energy, the electrode delivers a high-frequency alternating current to the immediate surrounding tissues. Inflow arrest was not routinely performed for ablations. The RFA was administered by means of 17-gauge multi-tined expandable RF needle electrodes (Med Italia Biomedica, Medolla, Italy) using an RF generator (RF2000; Boston Scientific, Marlborough, MA, USA). The formation of the typical hyperechoic peri-lesional cloud was monitored by IOUS.

Unit indications/contraindications for combined resection plus intraoperative RFA. Intraoperative thermal ablation was combined with liver resection (when deemed necessary), so as to avoid extensive hepatectomies particularly for deep liver metastases $<4 \mathrm{~cm}$ in diameter. For each patient, the decision to perform RFA in association with surgical ablation of the liver metastases was taken by a multidisciplinary team involving the surgeon, an interventional radiologist and an oncologist and was based upon both technical feasibility of the combined procedure and its potential cost-effectiveness.

If extrahepatic disease was present, liver resection was indicated for: i) resectable/ablatable pulmonary metastases; ii) resectable/ablatable isolated extrahepatic sites (e.g., ovary and lung); iii) local direct extension of liver metastases to the diaphragm and/or the adrenal gland that can be resected.

Contraindications to liver resection included uncontrolled extrahepatic disease such as widespread pulmonary disease; diffuse peritoneal disease; extensive nodal disease (such as retroperitoneal, mediastinal or portal nodes) or central nervous system metastases. All patients submitted to intraoperative RFA were followed-up by CT scan one month after the procedure to verify the completeness of necrosis of the lesion. For the purposes of the present study we divided patients into 2 groups: hepatic resection only (group 1) and hepatic resection plus RFA (group 2).

Definitions. Resections were defined in accordance with the Couinaud classification (25). Resection of segments 4 through 8 is referred to as an extended right hepatectomy; resection of segments 2 through 5 and 8 is an extended left hepatectomy. A right hepatectomy is a resection of segments 5 through 8; a left hepatectomy is resection of segments 2 through 4. Major hepatectomy was defined as resection of 3 or more segments. The largest resection was labelled as the primary procedure and additional smaller resections and ablations were labelled as secondary procedures. Bilobar tumour involvement was defined as tumour(s) involving any segments of the left and right hemiliver. Failure of ablative treatment was defined as incomplete ablation (judged on IOUS). In situ recurrence was defined as radiologic (CT or magnetic resonance imaging) and/or histologic (needle biopsy) detection of recurrent tumour at the original ablation site during follow-up. Radiologic proof was evaluated by sequential imaging demonstrating progression of disease. Synchronous disease was defined as the identification of liver metastases within 1 year from the date of resection of the primary colorectal carcinoma.

All complications and deaths within 30 days of surgery were considered as postoperative morbidity and mortality. Complications were graded on a scale of 1-5 according to a previously published grading system (26). Grade 1 complications are those that require only supportive care. Grade 2 complications require moderate interventions such as intravenous medications or prolonged tube feeding. Grade 3 complications require invasive surgical or radiologic intervention. Grade 4 complications produce chronic disability, and grade 5 complications result in death. Grades 1 and 2 were grouped as minor complications and grades 3-5 as major complications.

Statistical analysis. SPSS statistical software, version 12 (SPSS Inc, Chicago, IL, USA) was used for data analysis. Categorical variables were compared using the $\chi^{2}$ test and continuous variables were analyzed with the Wilcoxon rank-sum test. Survival comparisons were performed by the Kaplan-Meier method with comparisons made using the log-rank test where survival data were measured from the time of resection of the hepatic metastases. Results are reported as medians with ranges unless otherwise stated and P-values $<0.05$ are considered significant. 
Table I. Clinical features of patients sorted by treatment group.

\begin{tabular}{|c|c|c|c|}
\hline Features & Resection-only (n=280) & Resection + RFA (n=80) & P-value \\
\hline Age in years, mean (range) & $60(25-86)$ & $58(50-83)$ & 0.538 \\
\hline \multicolumn{4}{|l|}{ Gender } \\
\hline Male, n (\%) & $131(47.1)$ & $37(48)$ & \multirow[t]{2}{*}{1.000} \\
\hline Female, n (\%) & $149(52.9)$ & $43(52)$ & \\
\hline \multicolumn{4}{|l|}{ ASA score } \\
\hline $1-2, \mathrm{n}(\%)$ & $33(11.8)$ & 0 & \multirow[t]{2}{*}{0.132} \\
\hline $3-4, \mathrm{n}(\%)$ & $247(88.2)$ & $80(100)$ & \\
\hline \multicolumn{4}{|l|}{ T stage } \\
\hline $\mathrm{T} 1$ or $\mathrm{T} 2, \mathrm{n}(\%)$ & $48(16.6)$ & $5(5.9)$ & \multirow[t]{2}{*}{0.479} \\
\hline $\mathrm{T} 3$ or $\mathrm{T} 4, \mathrm{n}(\%)$ & $132(83.4)$ & $75(94.1)$ & \\
\hline \multicolumn{4}{|l|}{$\mathrm{N}$ stage } \\
\hline $0, \mathrm{n}(\%)$ & $86(30.6)$ & $14(17.6)$ & \multirow[t]{3}{*}{0.038} \\
\hline $1, \mathrm{n}(\%)$ & $133(47.5)$ & $23(29.4)$ & \\
\hline $2, \mathrm{n}(\%)$ & $61(21.9)$ & $43(52.9)$ & \\
\hline \multicolumn{4}{|l|}{ Timing of mts } \\
\hline Synchronous, n (\%) & $110(39.1)$ & $56(70.6)$ & \multirow[t]{2}{*}{0.018} \\
\hline Metachronous, n (\%) & $170(60.9)$ & $24(29.4)$ & \\
\hline CEA before resection, mean, $\mathrm{ng} / \mathrm{ml}$ & $6(0-786)$ & $2.5(0.7-274)$ & 0.315 \\
\hline Biggest metastatic volume in $\mathrm{cm}$, mean & $3(0.3-16)$ & $2.3(0.4-8)$ & 0.01 \\
\hline \multicolumn{4}{|l|}{ Single/multiple metastases } \\
\hline Single, n (\%) & $201(71.8)$ & $0(0)$ & \multirow[t]{2}{*}{$<0.001$} \\
\hline Multiple, n (\%) & $79(28.2)$ & $80(100 \%)$ & \\
\hline Number of treated lesions mean (range) & $1(1-6)$ & $4(2-10)$ & $<0.001$ \\
\hline \multicolumn{4}{|l|}{ Metastatic distribution } \\
\hline Bilobar, n (\%) & $36(12.9)$ & $61(76.5)$ & \multirow[t]{5}{*}{$<0.001$} \\
\hline Uni-lobar, n (\%) & $244(87.1)$ & $19(23.5)$ & \\
\hline Total treated lesions & 280 & 198 & \\
\hline Resection, n (\%) & $280(100)$ & $100(50.5)$ & \\
\hline RFA, n (\%) & $0(0)$ & $98(49.5)$ & \\
\hline Neoadjuvant chemotherapy, n (\%) & $148(52.9)$ & $47(58.8)$ & 0.800 \\
\hline \multicolumn{4}{|l|}{ Neoadjuvant chemotherapeutic response } \\
\hline Regression, n (\%) & $59(40.2)$ & $33(70)$ & \multirow[t]{3}{*}{0.152} \\
\hline Stable, n $(\%)$ & $54(36.8)$ & $4(8)$ & \\
\hline Progression, n (\%) & $34(23)$ & $10(22)$ & \\
\hline Simultaneous primary resection, $\mathrm{n}(\%)$ & & $21(26)$ & \\
\hline Preop. Portal vein embolization, n (\%) & & $7(8.75)$ & \\
\hline Extrahepatic resection, $\mathrm{n}(\%)$ & & $5(6)$ & \\
\hline Local invasion, n (\%) & & $3(4)$ & \\
\hline Histologic infiltration, n (\%) & & $2(2)$ & \\
\hline
\end{tabular}

\section{Results and Discussion}

Over the 20-year period there were 168 males and 162 females included with separation of cases into two main groups; group 1 with 280 patients undergoing resection only (mean age, 60 years; range $25-86$ years) and group 2 with 80 patients undergoing combined resection and RFA treatment (mean age, 58 years; range, $50-83$ years). Table I shows the patient characteristics and distribution of metastases amongst the two groups. In 61 patients $(76.5 \%)$, intraoperative RFA was used for centrally located tumours on the contralateral side of the primary resection that could not be safely removed by resection. Ten patients $(12.5 \%$ ) had extensively diseased parenchyma (steatosis) precluding further resection and 2 patients $(2.5 \%)$ 
Table II. Clinical results sorted by group.

\begin{tabular}{|c|c|c|c|}
\hline Clinical data & Resection-only $(\mathrm{n}=280)$ & Resection + RFA $(n=80)$ & P-value \\
\hline In-hospital stay, days, mean (range) & $8(5-28)$ & $9(5-32)$ & 0.01 \\
\hline Surgical procedure duration, min, mean (range) & $120(90-150)$ & $220(180-300)$ & \\
\hline Pringle maneuver duration min, mean (range) & $15(12-30)$ & $15(12-30)$ & \\
\hline Major hepatectomies, $\mathrm{n}$ (\% of total resections) & $147(37.5)$ & $14(8)$ & \\
\hline Extended hepatectomies, $\mathrm{n}(\%)$ & $13(8)$ & $0(0)$ & \\
\hline Hemi-hepatectomies, n (\%) & $16(10)$ & $0(0)$ & \\
\hline Segmentectomies (>2 seg), n (\%) & $25(15.5)$ & $14(8)$ & \\
\hline Minor resections, $\mathrm{n}$ (\% of total resections) & $133(34.5)$ & $86(23)$ & \\
\hline Lesser complications, $\mathrm{n}(\%)$ & $8(2.8)$ & $0(0)$ & 0.564 \\
\hline Severe complications, $\mathrm{n}(\%)$ & $10(3.5)$ & $0(0)$ & \\
\hline Blood loss in ml, mean (range) & $442(100-4000)$ & $288(100-800)$ & 0.269 \\
\hline Patients requiring transfusion, $\mathrm{n}(\%)$ & $39(14.7)$ & $0(0)$ & 0.089 \\
\hline Histologically + resection margins $(\mathrm{R} 1), \mathrm{n}(\%)$ & $67(24.1)$ & $19(23.5)$ & \\
\hline Hepatic in situ recurrence, n (\%; \% R1) & $4(1.5 ; 6)$ & $2(2.5 ; 10)$ & \\
\hline
\end{tabular}

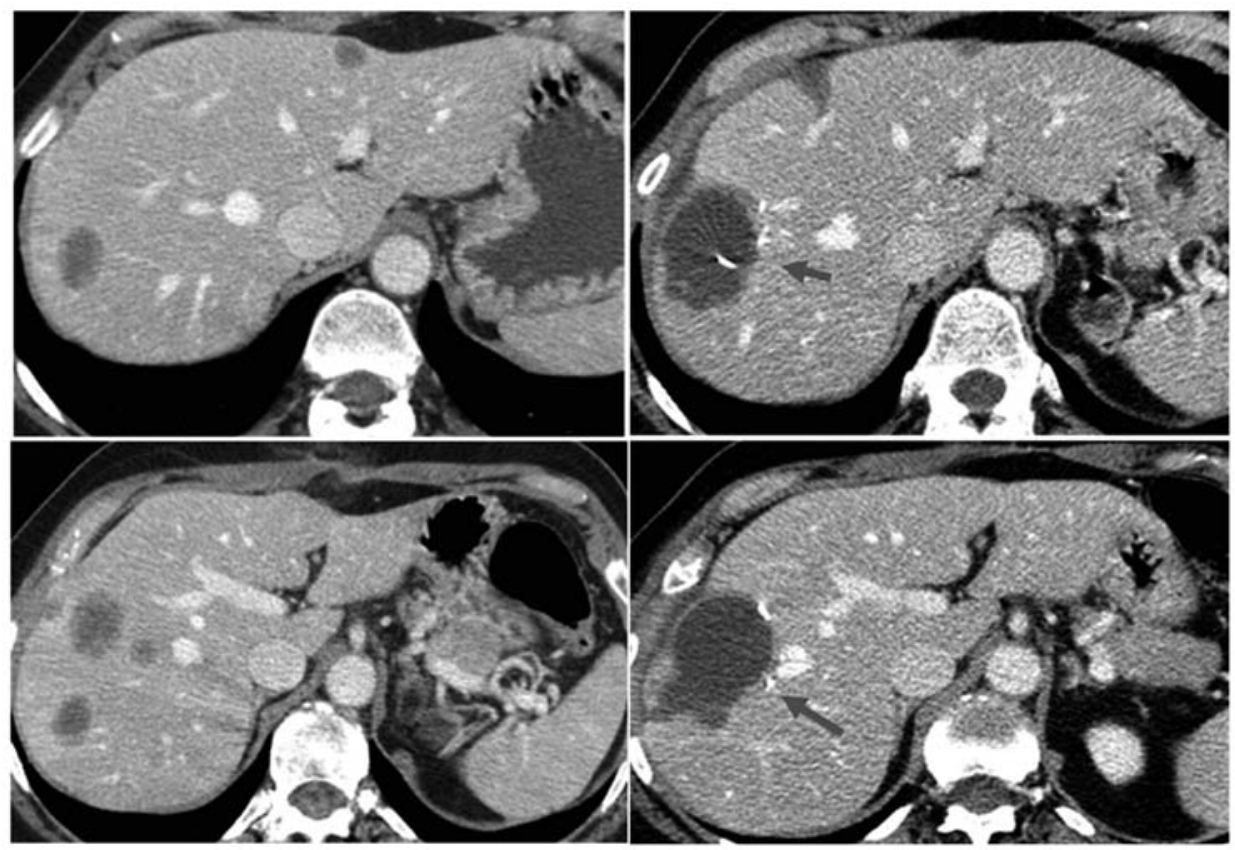

Figure 1. CT scan of metastatic lesions 23 days before (left column) and 10 days after (right column) RFA in a patient undergoing combined resectional plus thermo-ablative treatment. Arrows in the right hand images show extensive parenchymal scar formation following RFA treatment.

had tumour proximate to the inferior vena cava precluding a margin-negative resection. In 11 patients $(13.75 \%)$, the primary tumour was associated with regional lymph node metastases.

The median preoperative serum carcinoembryogenic antigen (CEA) level at the time of partial hepatectomy was $12 \mathrm{ng} / \mathrm{ml}$ (range, 3-21 ng/ml), with 29 patients (36\%) recording a level $>15 \mathrm{ng} / \mathrm{ml}$. Sixty-nine patients $(86 \%)$ presented with synchronous hepatic metastases. Neoadjuvant chemotherapy was administered in 18 patients $(22.5 \%)$, for a median period of 3 months (range, 2-6 months). Adjuvant chemotherapy following hepatic resection was administered to 69 patients (86\%). Overall, a total of 478 tumours were ablated; 98 (30.6\%) by RFA with 380 resections. Group 2 patients had a higher incidence of multiple metastases (100\% in group 2 vs. $28.2 \%$ in group 1, respectively; $\mathrm{P}<0.001)$ and bilobar involvement (76.5\% in group 2 vs. $12.9 \%$ in group 1 , respectively; $\mathrm{P}<0.001$ ) with a correspondingly higher mean number of lesions treated per patient $($ mean $=4$, range $2-10$ in group $2 \mathrm{vs}$. mean $=1$, range $1-6$ in group $1 ; \mathrm{P}<0.001)$. The timing of liver metastasis presentation influences the treatment type where synchronous metastases are more likely to be treated by combined therapy (70.6 vs. $39.1 \%$, respectively; $\mathrm{P}=0.018$ ).

Table II shows the type and extent of ablative procedure amongst the two groups. A total of 219 wedge resections were performed. This type of resection was the commonest type of procedure performed in group 2 cases (86/100). Overall, 


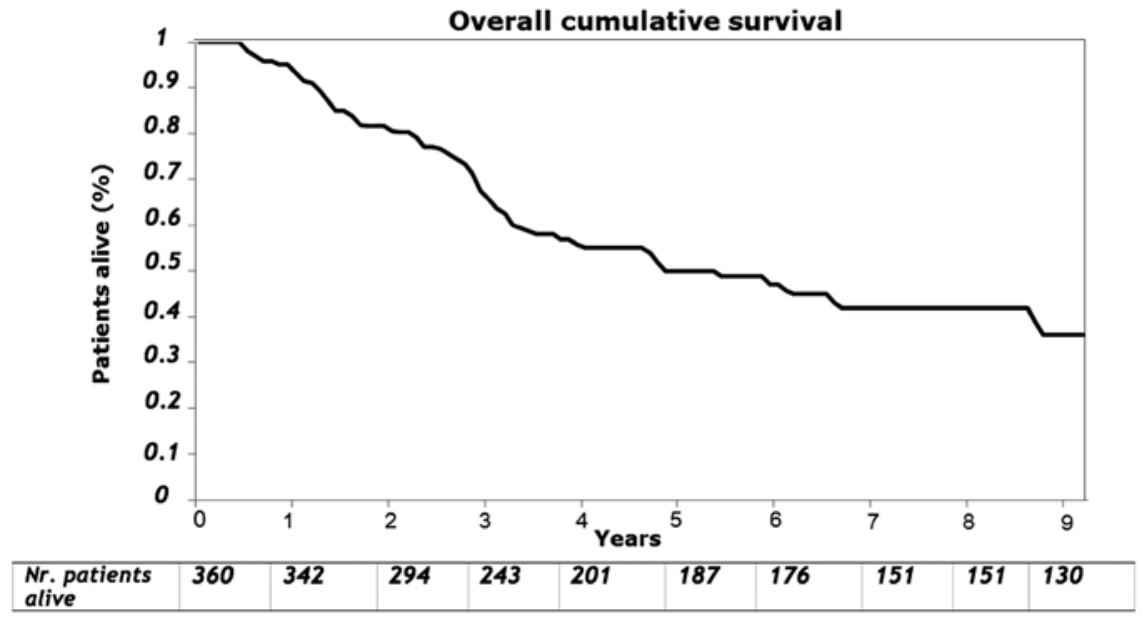

Figure 2. Cumulative overall survival at 3 and 5 years of the entire treated study population (62 and 50\%, respectively).

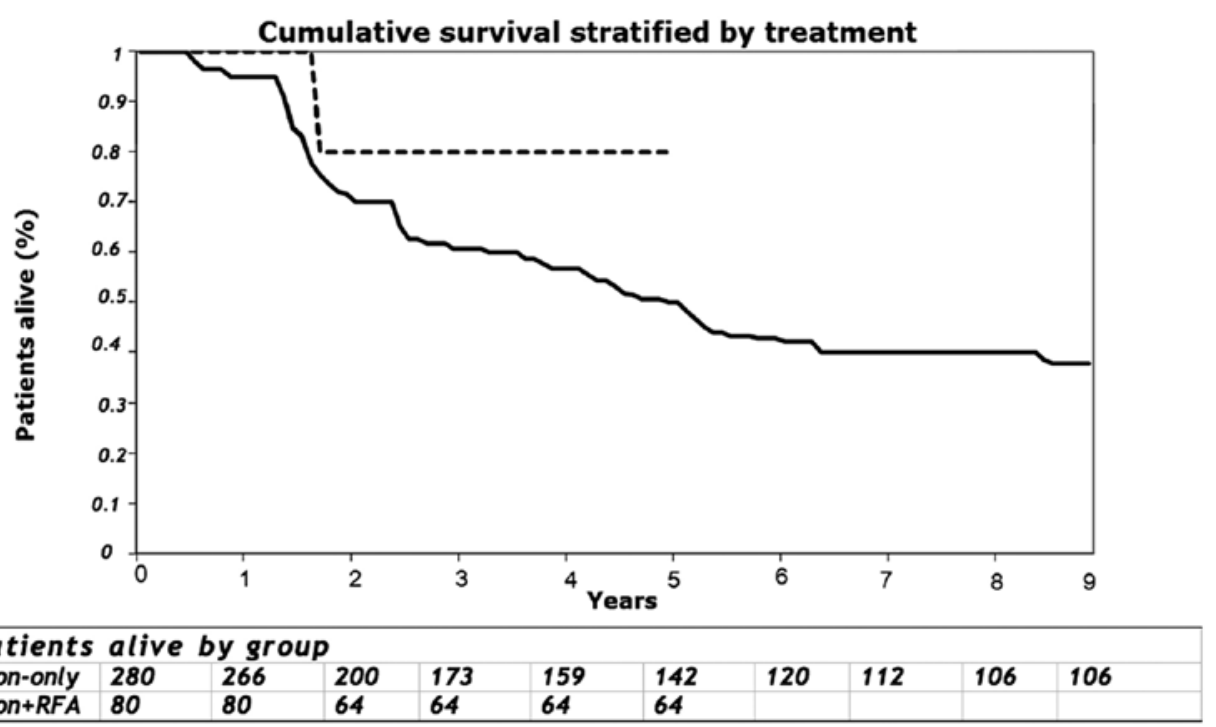

Figure 3. Cumulative overall survival at 3 years and 5 years for resected cases is represented by the continuous line (60 and $49 \%$, respectively). Cumulative overall survival at 3 years and 5 years for cases treated with resection plus thermo-ablation RFA is represented by the dashed line $(80$ and $80 \%$, respectively; $\mathrm{P}=0.193)$.

amongst the major hepatectomies, multiple segmentectomy was the most commonly performed procedure (39 cases or $24 \%$ of the total hepatic resections) with 25 such procedures being performed in group 1 cases $(8 \%$ of total hepatic resections). Extended hepatectomies and hemihepatectomies were performed in 13 and 8 patients, respectively (all within group 1) representing 8 and $10 \%$, respectively, of all resections performed. Histologically involved surgical margins were found in $67(24.1 \%)$ of the resection only group 1 cases and in $19(23.5 \%)$ of the combined treatment group 2 cases.

Concerning perioperative data for the resectional group, the median operative time was $120 \mathrm{~min}$ (range, 90-150 min) for group 1 patients whereas combined resection and RFA treatment took a median of $220 \mathrm{~min}$ (range, 180-300 $\mathrm{min}$ ). The median duration of the Pringle maneuver (when used) for both groups was $15 \mathrm{~min}$ (range, 10-32 min). The median intraoperative estimated blood loss was $250 \mathrm{ml}$ (range, 50-1200 ml), with a median postoperative hospital stay of 8 days (range, 5-28) for resection only cases and 9 days (5-32) for those who had RFA in addition to resection. There was no perioperative mortality with a per-operative complication rate of $6 \%$ (18/280 cases) which included 5 bile leaks, 3 patients with atrial fibrillation, 1 patient with a postoperative myocardial infarction, 2 patients with transient hepatic dysfunction and a further 2 cases with postoperative ileus. Six patients in the hepatic resection only group developed postoperative infectious complications (1 bile leak, 3 pleural effusions, 1 bronchopneumonia and 1 wound infection). There were no RFA-associated complications or complications in the combined treatment group. Fig. 1 shows an example of the effect of RFA thermo-ablation on different hepatic lesions in a single patient treated with combined resection and RFA (segments V, VII and VII), as they appear on CT scan ten days after surgery.

The median follow-up for survivors was 90 months (range, 1-180 months). For the entire group as measured from the time of hepatic resection, the overall 3- and 5-year survival was 70 and 50\%, respectively (Fig. 2). The 5-year survival for group 1 and group 2 was 49 and $80 \%$, respectively ( $\mathrm{P}=0.193$; Fig. 3 ). 
Table III. Global 5-year survival predictors - univariate analysis.

\begin{tabular}{|c|c|c|}
\hline Survival predictors & $\begin{array}{l}\text { Global 5-year } \\
\text { survival (\%) }\end{array}$ & P-value \\
\hline \multicolumn{3}{|l|}{ Procedure } \\
\hline Resection-only & 48.6 & 0.193 \\
\hline Resection + RFA & 80 & \\
\hline \multicolumn{3}{|l|}{ Gender } \\
\hline Male & 39 & 0.271 \\
\hline Female & 55.4 & \\
\hline \multicolumn{3}{|c|}{$\mathrm{N}$-positive primitive tumour } \\
\hline No & 57.8 & 0.331 \\
\hline Yes & 47.2 & \\
\hline \multicolumn{3}{|l|}{ Metastatic timing } \\
\hline Syncronous & 43.4 & 0.539 \\
\hline Metacronous & 51 & \\
\hline \multicolumn{3}{|l|}{ Bilateral distribution } \\
\hline Yes & 66 & 0.162 \\
\hline No & 47 & \\
\hline \multicolumn{3}{|l|}{ Number of lesions } \\
\hline$>3$ & 48.9 & 0.41 \\
\hline$<3$ & 50.9 & \\
\hline \multicolumn{3}{|c|}{ Volume of lesions (cm) } \\
\hline$<5$ & 52.7 & 0.161 \\
\hline$>5$ & 34.7 & \\
\hline \multicolumn{3}{|c|}{ Histologically involved margins } \\
\hline No & 51 & \\
\hline Yes & 46 & 0.73 \\
\hline \multicolumn{3}{|c|}{ Neoadjuvant chemotherapy } \\
\hline No & 51.8 & 0.794 \\
\hline Yes & 45.3 & \\
\hline \multicolumn{3}{|c|}{ Adjuvant chemotherapy } \\
\hline No & 65.4 & 0.015 \\
\hline Yes & 43.1 & \\
\hline
\end{tabular}

On univariate analysis, tumour size exceeding $5 \mathrm{~cm}$, a positive resection margin, positive nodal status of the primary, tumour number and the preoperative CEA level were not associated with survival (Table III). For those undergoing RFA treatment, the number of lesions, a size of lesion exceeding $2 \mathrm{~cm}$ in maximal diameter or proximity to major vessels were not associated with overall survival. The median disease-free survival measured from the time of hepatic resection for the patients with complete gross resection was 30 months (range, 1-180 months), with an actuarial disease-free survival of $50 \%$ at 1 year, $43 \%$ at 2 years and $34 \%$ at 3 years (Fig. 4). The median hepatic disease-free survival was 20 months (range, 0-160 months) where 91 patients $(66 \%)$ had hepatic recurrence at the time of last follow-up (Fig. 5). The disease-free survival of patients treated with combined resection and RFA was higher than that of the resection-alone group at 3 years $(50$ vs. $37.14 \%$, respectively; $\mathrm{P}=0.48)$ and at 5 years $(50$ vs. $33.9 \%$, respectively; $\mathrm{P}=0.069)$. Overall, disease recurred in 169 of the 280 patients undergoing complete gross resection $(70 \%)$ where 111 patients $(30 \%)$ had no signs of recurrence at their last follow-up. The only intraoperative thermo-ablation failure was for a large lesion $5 \mathrm{~cm}$ in maximal diameter. Amongst the group 1 patients where there was histological margin involvement ( $\mathrm{R} 1$ resections) there were 4 in-liver recurrences representing $1.5 \%$ of the total resection group or $6 \%$ of $\mathrm{R} 1$ resections. Amongst the group 2 cases there were 19 with histological involvement of their resection margins with 2 cases of in liver recurrence (both at the site of the previous resection), representing recurrence in only $2.5 \%$ of group 2 patients or $10 \%$ of all $\mathrm{R} 1$ resections.

This single unit retrospective analysis showed similar overall and disease-free survival between patients with hepatic colorectal metastases undergoing hepatic resection and those receiving combined hepatic resection with RFA treatment, despite the finding that patients having the combined treatment overall had more hepatic lesions. Colorectal cancer (CRC) is the 3rd leading cause of cancer death, with one-quarter of CRC patients presenting with metastases where over recent years there has been a generally more aggressive attitude towards surgical metastasis excision $(5,27)$. In this context, R0 marginfree surgical resection remains the only potentially curative treatment available although only between 10 and $20 \%$ of patients will actually be suitable for this approach. A variety of ablative therapies including chemical ablation, cryosurgery, thermo-ablation (radiofrequency ablation-RFA and microwave therapy) and electroporation have been advocated for hepatic metastatic CRC with each modality having particular indications and contraindications (28). The commonest treatments with available outcome data are RFA and cryoablation. Such ablative therapies have traditionally been used in the treatment of hepatic metastatic CRC for the local control of unresectable disease, however, they have also been employed selectively as an adjunct to hepatic resection in an attempt to enhance the potential resectability of some metastatic tumors (29).

Several clinical questions remain concerning the wider use of RFA in hepatic metastatic CRC. The first question is whether RFA is equivalent to resection in clearly resectable cases. In this respect, there are considerable data showing higher local recurrence and reduced survival for RFA-only treated cases although it is accepted that patients undergoing potentially curative hepatic resections and those treated with ablative therapies are not strictly comparable (30). Concerning this point, however, a recent Cochrane Library review concluded that the therapeutic use of RFA as a definitive alternative to resection remains unproven (31). The second question is whether RFA can extend the pool of resectable cases. Attempts to assess this question through randomized controlled trials have failed with the French FFCD trial which compared RFA with resection closing in 2004 (32) and the EORTC-CLOCC trial which compared RFA with chemotherapy in cases deemed unresectable being downscaled from a phase III to a phase II study and closing early in 2006 because of poor recruitment (33). The extended use of RFA as an adjunct to resection appears to be gaining worldwide acceptance with a respectable safety profile $(8,11)$ although its efficacy is controversial because of relatively high reported rates of intrahepatic recurrence either at or distant from the ablation sites (34). 


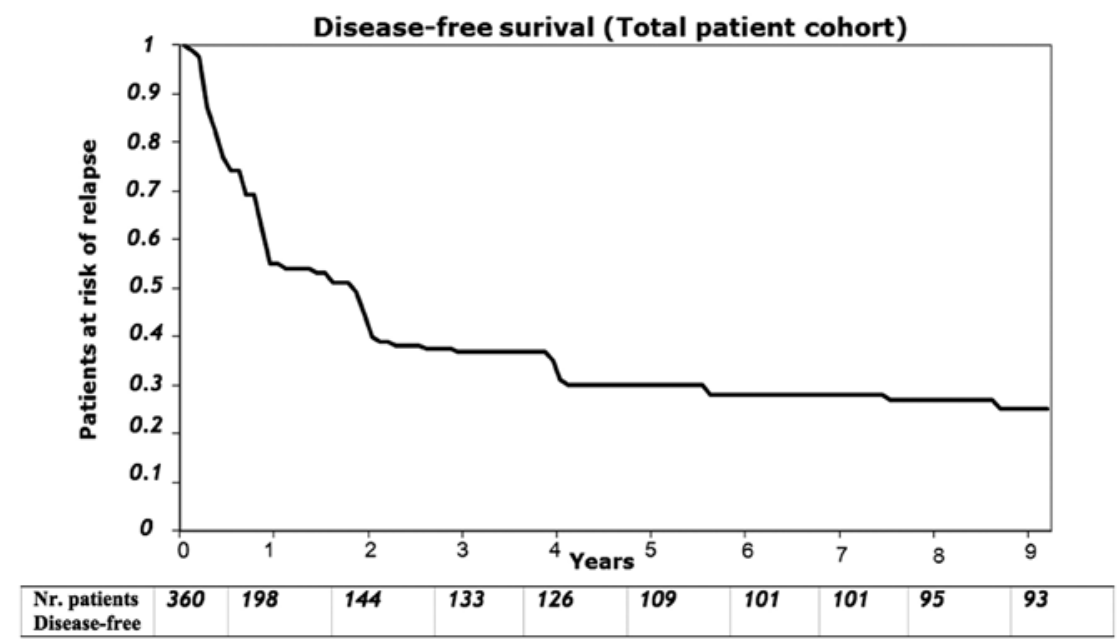

Figure 4. Disease-free survival (DFS) of the entire treatment (3-year 37.5 with 30\% remaining disease-free at the 5-year assessment).

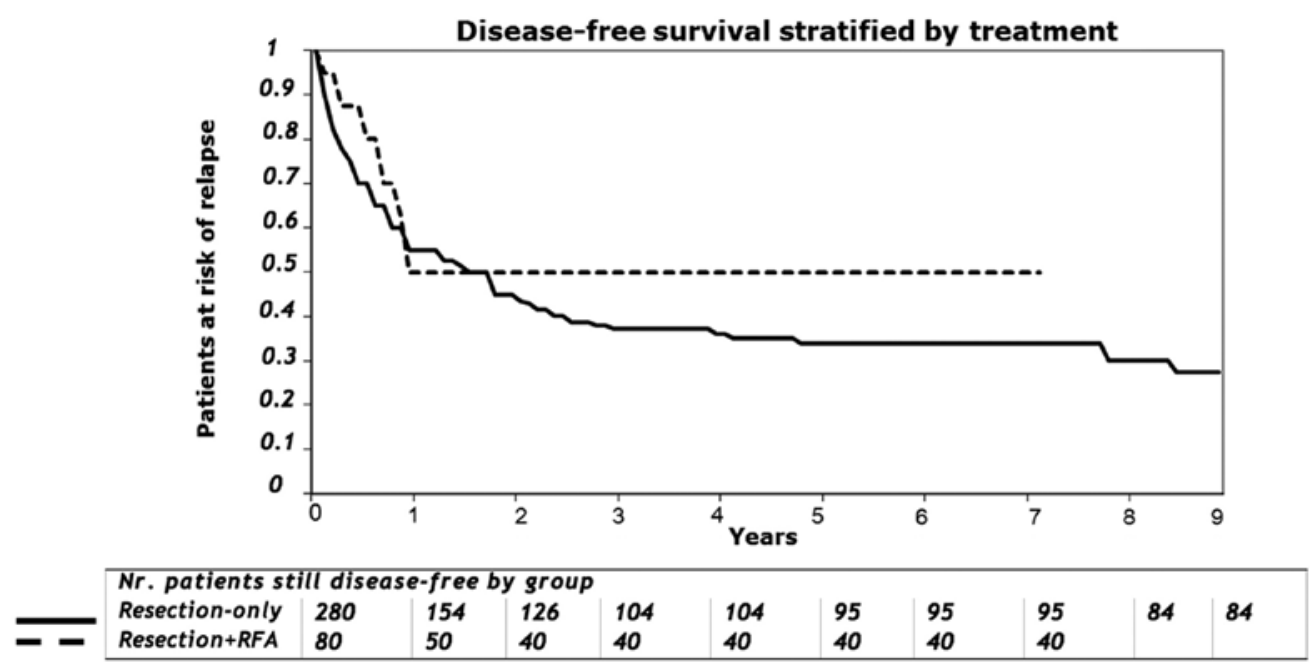

Figure 5. Disease-free survival stratified by treatment. Following a similar 50\% drop-off during the first twelve months, the other half of the combinedtreatment patients (dashed line) is still disease-free at 3 and 5 years, whereas only $37 \%$ of patients who have undergone resection alone (continuous line) have not relapsed at 3 years and only $34 \%$ are relapse-free at 5 years.

Data specifically assessing the role of combined resection plus RFA in metastatic CRC are currently limited and non-randomized (Table IV) and the reported oncologic outcomes are mixed. Early studies by Elias et al $(14,15)$ and Pawlik et al (16) reported the safety of single-arm studies which combined resection with RFA; an effect confirmed in a later non-randomized single-arm analysis by Evrard et al (21) which assessed RFA use in a single surgical unit for unresectable hepatic disease. Although patients can achieve prolonged survival with this approach, the low early event-free survival rate reported in this study suggests that they are rarely cured from their hepatic disease if it is initially deemed unresectable.

Abdalla et al (17) and Kornprat and colleagues (18) both independently showed higher intrahepatic recurrence rates and survival disadvantage if combination therapies were used whereas similar to the present study, others have been unable to demonstrate any deleterious survival effect if RFA is added to resection specifically if it is applied in patients presenting with bilobar disease $(20,22)$. The present study showed an in liver recurrence rate that did not differ between resection only and combined management cases and that was similar to other studies (19-21,23). Variations in the patterns of recurrence in the differently managed groups will most likely reflect a worse tumour biology where recurrences are relatively uncommon at the RFA-treated sites but where RFA-managed patients tend to have higher rates of extrahepatic failure $(19,30)$.

These studies should be interpreted with caution as they have considerable heterogeneity, with variations in the technical radiofrequency approach (percutaneous, laparoscopic or open) and with the type of RFA probe used (35-37). Also, these variant RFA approaches are not strictly comparable and each has particular advantages and disadvantages. Percutaneous RFA for example, is unable to directly assess the zone of thermal injury and is less reliable when a lesion is subcapsular or adjacent to other viscera. By contrast, open RFA can be used concomitantly with intra-abdominal staging, at the time of temporary hepatic inflow occlusion and during selective synchronous resections of the colorectal primary.

Overall, RFA appears to be a safe ablative modality where decision making concerning the different forms of 
Table IV. Available literature comparing hepatic resection with combined resection and radiofrequency ablation for patients with metastatic colorectal cancer.

\begin{tabular}{|c|c|c|c|c|c|}
\hline Author, year (Ref.) & Trial design & $\mathrm{N}$ & $\begin{array}{l}\text { Follow-up } \\
\text { (months) }\end{array}$ & $\begin{array}{c}\text { Intrahepatic recurrence } \\
\text { rate }(\%)\end{array}$ & $\begin{array}{l}\text { Overall 3-year } \\
\text { survival (\%) }\end{array}$ \\
\hline Elias et al, 2000 (15) & $\mathrm{R}+\mathrm{RFA}$ & 21 & 17 & 42 & 94.7 \\
\hline Pawlik et al, 2003 (16) & $\mathrm{R}+\mathrm{RFA}$ & 172 & 21.3 & 47 & 65.2 \\
\hline Abdalla et al, 2004 (17) & $\begin{array}{l}\mathrm{R} \\
\mathrm{R}+\mathrm{RFA}\end{array}$ & $\begin{array}{l}190 \\
101\end{array}$ & 21 & $\begin{array}{l}11 \\
28\end{array}$ & $\begin{array}{l}73 \\
43\end{array}$ \\
\hline Kornprat et al, 2007 (18) & $\mathrm{R}+$ Ablation $^{\mathrm{a}}$ & 39 & 21.1 & 14 & 47 \\
\hline Gleisner et al, 2008 (19) & $\begin{array}{l}\mathrm{R} \\
\mathrm{R}+\mathrm{RFA}\end{array}$ & $\begin{array}{r}192 \\
55\end{array}$ & N.R. & $\begin{array}{l}14.8 \\
50.9\end{array}$ & $\begin{array}{l}74.1 \\
44.9\end{array}$ \\
\hline Leung et al, 2010 (20) & $\begin{array}{l}\mathrm{R} \\
\mathrm{R}+\mathrm{RFA}\end{array}$ & $\begin{array}{l}84 \\
16\end{array}$ & 37 & $\begin{array}{l}55.9 \\
62.5\end{array}$ & $\begin{array}{l}54 \\
38\end{array}$ \\
\hline Evrard et al, 2012 (21) & $\mathrm{R}+\mathrm{RFA}$ & 42 & 35 & 57 & 43 \\
\hline Karanicolas et al, 2013 (22) & $\begin{array}{l}\mathrm{R} \\
\mathrm{R}+\mathrm{RFA}\end{array}$ & $\begin{array}{r}141 \\
95\end{array}$ & $\begin{array}{l}44 \\
23\end{array}$ & N.R. & $\begin{array}{l}67 \\
77\end{array}$ \\
\hline Eltawil et al, 2014 (23) & $\begin{array}{l}\mathrm{R} \\
\mathrm{R}+\mathrm{RFA}\end{array}$ & $\begin{array}{r}150 \\
24\end{array}$ & $\begin{array}{l}35 \\
36\end{array}$ & $\begin{array}{l}25.3 \\
50\end{array}$ & $\begin{array}{l}65.5 \\
61.4\end{array}$ \\
\hline Current series & $\begin{array}{l}\mathrm{R} \\
\mathrm{R}+\mathrm{RFA}\end{array}$ & $\begin{array}{r}280 \\
80\end{array}$ & $\begin{array}{l}90 \\
84\end{array}$ & $\begin{array}{l}60 \\
50\end{array}$ & $\begin{array}{l}70 \\
50\end{array}$ \\
\hline
\end{tabular}

$\mathrm{R}$, hepatic resection; RFA, radiofrequency ablation.

ablation available reflects both inherent instrumental safety profiles and specific clinical scenarios. By contrast to RFA, serious adverse events have been reported with cryosurgical ablation (CSA), including a cryoshock syndrome, significant haemorrhage following ice ball cracking and the development of hepatic abscesses $(10,11)$. Limited retrospective data comparing RFA with CSA have reported higher complication rates, more extensive blood loss and a more prolonged length of hospital stay in those patients treated with CSA (38). Non-thermal ablative techniques in particular will have a role in those cases presenting with large central tumours located near great vessels where RFA efficacy would be diminished by a well-described 'heat-sink' effect of cooling local blood flow $(8,28,39,40)$.

The oncologic efficacy of thermo-ablative techniques is influenced by various tumour-related factors, including the number of lesions, their size and their proximity to larger vessels $(11,14,17,41)$. In this regard, treatment by RFA of hepatic tumours exceeding $3 \mathrm{~cm}$ in maximal diameter remains a significant challenge. The only RFA in-liver recurrence in our series occurred at the ablation site of a lesion which was $5 \mathrm{~cm}$ in size. Larger lesions are more amenable to CSA because multiple probes can be placed simultaneously where in this setting the hypoechoic changes induced by the iceball can be readily visualized with ultrasound. The use of CSA is also preferable to define margin enhancement when a lesion has been excised with suboptimal margins making CSA currently the only described method of achieving long- term survival in patients where margins are histologically involved (42). Alternatively in those cases managed with RFA, in order to minimize treatment failure in the smaller tumors, future analysis will be required of the efficacy of the newer electrodes which are capable of inducing larger coagulation zones. For centrally located larger tumours on the contralateral side of a primary resection that cannot be surgically removed whilst preserving a sufficient functional liver remnant, RFA combined with temporary hepatic inflow occlusion designed to diminish ablative heat loss may potentially prove the best management option (43).

In conclusion, the present study has the major limitations of being a retrospective review of non-randomized cases. Given that the number of tumour deposits and their size correlate with a worse survival and that RFA-treated cases tend more often to have multiple tumours, bilateral disease and larger lesions, strict comparison of treated groups will be flawed because of poor patient matching. This has resulted in an inability to conduct randomized trials incorporating combined therapy in one treatment arm (44) where closer matching although resulting in enhanced internal comparability actually reduces the generalizability of the data (30). In order to overcome this matching bias, Gleisner et al (19) used the more rigorous technique of propensity score analysis designed to determine the likelihood that a patient will receive a specific treatment by creating a single predictor which reflected all of the confounding clinicopathological variables (45). Even this approach will have limitations if the studied populations 
(resection vs. combined resection plus RFA) have relatively poor overlap of their characteristics such that the baseline features will be so different between the groups that no causal conclusions concerning the differential effects of the treatment can be effectively drawn.

In summary, our data support the use of RFA when complete resection of an hepatic metastasis from CRC cannot be achieved. The combination of resection with ablation shows equivalent recurrence rates when compared with resection alone and does not appear to compromise cancer-specific survival. Despite an inability to adequately randomize patients to different treatment arms, a more extended use of RFA in cases initially deemed unresectable will at least define standards during ablation both for RFA technique and for real-time ultrasonographic monitoring during such procedures.

\section{References}

1. Boyle P and Ferlay J: Cancer incidence and mortality in Europe, 2004. Ann Oncol 16: 481-488, 2005.

2. Kemeny N: Management of liver metastases from colorectal cancer. Oncology (Williston Park) 20: 1161-1176, 1179, discussion 1179-1180, 1185-1186, 2006.

3. Yoo PS, Lopez-Soler RI, Longo WE and Cha CH: Liver resection for metastatic colorectal cancer in the age of neoadjuvant chemotherapy and bevacizumab. Clin Colorectal Cancer 6: 202-207, 2006.

4. Chiappa A, Makuuchi M, Lygidakis NJ, Zbar AP, Chong G, Bertani E, Sitzler PJ, Biffi R, Pace U, Bianchi PP, et al: The management of colorectal liver metastases: Expanding the role of hepatic resection in the age of multimodal therapy. Crit Rev Oncol Hematol 72: 65-75, 2009.

5. Akgül Ö, Çetinkaya E, Ersöz Ș and Tez M: Role of surgery in colorectal cancer liver metastases. World J Gastroenterol 20 : 6113-6122, 2014

6. Adam R, Miller R, Pitombo M, Wicherts DA, de Haas RJ, Bitsakou G and Aloia T: Two-stage hepatectomy approach for initially unresectable colorectal hepatic metastases. Surg Oncol Clin N Am 16: 525-536, viii, 2007.

7. Simoneau E, Hassanain M, Shaheen M, Aljiffry M, Molla N, Chaudhury P, Anil S, Khashper A, Valenti D and Metrakos P: Portal vein embolization and its effect on tumour progression for colorectal cancer liver metastases. Br J Surg 102: 1240-1249, 2015.

8. Lahat E, Eshkenazy R, Zendel A, Zakai BB, Maor M, Dreznik Y and Ariche A: Complications after percutaneous ablation of liver tumors: A systematic review. Hepatobiliary Surg Nutr 3: 317-323, 2014.

9. Kerkar S, Carlin AM, Sohn RL, Steffes C, Tyburski J, Littrup P and Weaver D: Long-term follow up and prognostic factors for cryotherapy of malignant liver tumors. Surgery 136: 770-779, 2004.

10. Seifert JK, Springer A, Baier P and Junginger T: Liver resection or cryotherapy for colorectal liver metastases: A prospective case control study. Int J Colorectal Dis 20: 507-520, 2005.

11. Bilchik AJ, Wood TF, Allegra D, Tsioulias GJ, Chung M, Rose DM, Ramming KP and Morton DL: Cryosurgical ablation and radiofrequency ablation for unresectable hepatic malignant neoplasms: A proposed algorithm. Arch Surg 135: 657-662, discussion 662-664, 2000.

12. Mulier S, Mulier P, Ni Y, Miao Y, Dupas B, Marchal G, De Wever I and Michel L: Complications of radiofrequency coagulation of liver tumours. Br J Surg 89: 1206-1222, 2002.

13. Curley SA, Marra P, Beaty K, Ellis LM, Vauthey JN, Abdalla EK Scaife C, Raut C, Wolff R, Choi H, et al: Early and late complications after radiofrequency ablation of malignant liver tumors in 608 patients. Ann Surg 239: 450-458, 2004.

14. Elias D, Baton O, Sideris L, Boige V, Malka D, Liberale G, Pocard $\mathrm{M}$ and Lasser P: Hepatectomy plus intraoperative radiofrequency ablation and chemotherapy to treat technically unresectable multiple colorectal liver metastases. J Surg Oncol 90: 36-42, 2005.
15. Elias D, Goharin A, El Otmany A, Taieb J, Duvillard P, Lasser P and de Baere T: Usefulness of intraoperative radiofrequency thermoablation of liver tumours associated or not with hepatectomy. Eur J Surg Oncol 26: 763-769, 2000.

16. Pawlik TM, Izzo F, Cohen DS, Morris JS and Curley SA Combined resection and radiofrequency ablation for advanced hepatic malignancies: Results in 172 patients. Ann Surg Oncol 10: 1059-1069, 2003.

17. Abdalla EK, Vauthey JN, Ellis LM, Ellis V, Pollock R, Broglio KR, Hess K and Curley SA: Recurrence and outcomes following hepatic resection, radiofrequency ablation, and combined resection/ablation for colorectal liver metastases. Ann Surg 239: 818-825, discussion 825-827, 2004.

18. Kornprat P, Jarnagin WR, DeMatteo RP, Fong Y, Blumgart LH and D'Angelica M: Role of intraoperative thermoablation combined with resection in the treatment of hepatic metastasis from colorectal cancer. Arch Surg 142: 1087-1092, 2007.

19. Gleisner AL, Choti MA, Assumpcao L, Nathan H, Schulick RD and Pawlik TM: Colorectal liver metastases: Recurrence and survival following hepatic resection, radiofrequency ablation, and combined resection-radiofrequency ablation. Arch Surg 143: 1204-1212, 2008.

20. Leung EY, Roxburgh CS, Leen E and Horgan PG: Combined resection and radiofrequency ablation for bilobar colorectal cancer liver metastases. Hepatogastroenterology 57: 41-46, 2010.

21. Evrard S, Rivoire M, Arnaud JP, Lermite E, Bellera C, Fonck M, Becouarn Y, Lalet C, Puildo M and Mathoulin-Pelissier S: Unresectable colorectal cancer liver metastases treated by intraoperative radiofrequency ablation with or without resection. Br J Surg 99: 558-565, 2012.

22. Karanicolas PJ, Jarnagin WR, Gonen M, Tuorto S, Allen PJ, DeMatteo RP, D'Angelica MI and Fong Y: Long-term outcomes following tumor ablation for treatment of bilateral colorectal liver metastases. JAMA Surg 148: 597-601, 2013.

23. Eltawil KM, Boame N, Mimeault R, Shabana W, Balaa FK, Jonker DJ, Asmis TR and Martel G: Patterns of recurrence following selective intraoperative radiofrequency ablation as an adjunct to hepatic resection for colorectal liver metastases. J Surg Oncol 110: 734-738, 2014.

24. Chiappa A, Bertani E, Makuuchi M, Zbar AP, Contino G, Viale G, Pruneri G, Bellomi M, Della Vigna P, Zampino MG, et al: Neoadjuvant chemotherapy followed by hepatectomy for primarily resectable colorectal cancer liver metastases. Hepatogastroenterology 56: 829-834, 2009.

25. Couinaud C: Anatomic principles of left and right regulated hepatectomy: Technics. J Chir (Paris) 70: 933-966, 1954 (in French).

26. Martin RC II, Brennan MF and Jaques DP: Quality of complication reporting in the surgical literature. Ann Surg 235: 803-813, 2002.

27. Ito K, Govindarajan A, Ito $\mathrm{H}$ and Fong Y: Surgical treatment of hepatic colorectal metastasis: Evolving role in the setting of improving systemic therapies and ablative treatments in the $21 \mathrm{st}$ century. Cancer J 16: 103-110, 2010.

28. Singla S, Hochwald SN and Kuvshinoff B: Evolving ablative therapies for hepatic malignancy. BioMed Res Int 2014: 230174 , 2014.

29. Lee KH, Kim HO, Yoo CH, Son BH, Park YL, Cho YK, Kim H and Han WK: Comparison of radiofrequency ablation and resection for hepatic metastasis from colorectal cancer. Korean J Gastroenterol 59: 218-223, 2012.

30. Tsai S and Pawlik TM: Outcomes of ablation versus resection for colorectal liver metastases: Are we comparing apples with oranges? Ann Surg Oncol 16: 2422-2428, 2009.

31. Cirocchi R, Trastulli S, Boselli C, Montedori A, Cavaliere D, Parisi A, Noya G and Abraha I: Radiofrequency ablation in the treatment of liver metastases from colorectal cancer. Cochrane Database Syst Rev 2012: Article no. CD006317. doi: 10.1002/14651858.CD006317.pub3.

32. Benoist $\mathrm{S}$ and Nordlinger B: Radiofrequency ablation in liver tumours. Ann Oncol 15 (Suppl 4): iv313-iv317, 2004.

33. Ruers T, Punt CJ, van Coeverden F, Borel Rinkes I, Lederman JA, Poston GJ, Bechstein W, Lentz M, Mauer M, Nordlinge B, et al: Final results of the EORTC intergroup randomized study 40004 (CLOCC) evaluating the benefit of radiofrequency ablation (RFA) combined with chemotherapy for unresectable colorectal liver metastases (CRC LM). J Clin Oncol 28 (Suppl): 3526A, 2010. 
34. Nielsen K, van Tilborg AA, Meijerink MR, Macintosh MO, Zonderhuis BM, de Lange ES, Comans EF, Meijer S and van den Tol MP: Incidence and treatment of local site recurrences following RFA of colorectal liver metastases. World J Surg 37: 1340-1347, 2013.

35. Machi J, Uchida S, Sumida K, Limm WM, Hundahl SA, Oishi AJ, Furumoto NL and Oishi RH: Ultrasound-guided radiofrequency thermal ablation of liver tumors: Percutaneous, laparoscopic, and open surgical approaches. J Gastrointest Surg 5: 477-489, 2001.

36. Ahmad A, Chen SL, Kavanagh MA, Allegra DP and Bilchik AJ: Radiofrequency ablation of hepatic metastases from colorectal cancer: Are newer generation probes better? Am Surg 72 875-879, 2006

37. Eisele RM, Neumann U, Neuhaus P and Schumacher G: Open surgical is superior to percutaneous access for radiofrequency ablation of hepatic metastases. World J Surg 33: 804-811, 2009.

38. Pearson AS, Izzo F, Fleming RYD, Ellis LM, Delrio P, Roh MS Granchi $J$ and Curley SA: Intraoperative radiofrequency ablation or cryoablation for hepatic malignancies. Am J Surg 178: 592-599, 1999.

39. Stoltz A, Gagnière J, Dupré A and Rivoire M: Radiofrequency ablation for colorectal liver metastases. J Visc Surg 151 (Suppl 1) S33-S44, 2014.
40. Pillai K, Akhter J, Chua TC, Shehata M, Alzahrani N, Al-Alem I and Morris DL: Heat sink effect on tumor ablation characteristics as observed in monopolar radiofrequency, bipolar radiofrequency, and microwave, using ex vivo calf liver model. Medicine (Baltimore) 94: e580, 2015.

41. Mulier S, Ni Y, Jamart J, Ruers T, Marchal G and Michel L: Local recurrence after hepatic radiofrequency coagulation: Multivariate meta-analysis and review of contributing factors. Ann Surg 242: 158-171, 2005.

42. Dwerryhouse SJ, Seifert JK, McCall JL, Iqbal J, Ross WB and Morris DL: Hepatic resection with cryotherapy to involved or inadequate resection margin (edge freeze) for metastases from colorectal cancer. Br J Surg 85: 185-187, 1998.

43. Nikfarjam M, Muralidharan V, Malcontenti-Wilson C, McLaren W and Christophi C: Impact of blood flow occlusion on liver necrosis following thermal ablation. ANZ J Surg 76: 84-91, 2006.

44. Curley SA: Radiofrequency ablation versus resection for resectable colorectal liver metastases: Time for a randomized trial? Ann Surg Oncol 15: 11-13, 2008.

45. Rubin DB: Estimating causal effects from large data sets using propensity scores. Ann Intern Med 127: 757-763, 1997. 